\title{
Facilitators and Barriers to Positive Experiences for Families of Individuals with Autism
}

\author{
Jill C. Fodstad ${ }^{1,2}$
}

Accepted: 7 August 2021 / Published online: 18 August 2021

(C) The Author(s), under exclusive licence to Springer Science+Business Media, LLC, part of Springer Nature 2021

This Special Issue of curated articles in the Review Journal of Autism and Developmental Disorders (RJAD) focuses on families of individuals with autism spectrum disorder (ASD). Research on the shared experiences of family members of a person with ASD is not a new area in our field but is one that receives less focus when compared to the vast amount of literature focusing on the affected individual. Parents and siblings typically play the most vital roles in the lives of persons with ASD. Advocating and supporting a child or sibling with ASD across the lifespan has been noted to be related to an elevated level of individual and overall family strain (Begum \& Mamin, 2019; Karst \& Van Hecke, 2012; Sim et al., 2018). To be best able to support the needs of persons with ASD, we must also embrace and support those who are most critical to their success and well-being - their family. Thus, the purpose of this special issue is to highlight the needs, experiences, and outcomes of parents and siblings of individuals with ASD.

This Special Issue is different from many special issues in that the articles contained here were not submitted upon a targeted call for topically focused papers. Rather, the review articles in this issue are ones that were collated from already accepted articles which were ready for publication in RJAD's que. While this may not seem noteworthy, I believe it demonstrates the improved recognition and focus on the needs of families. This collection of ten high-quality review articles generates a summary of important evidence demonstrating the facilitators and barriers to positive experiences and outcomes for the family members of a person with ASD. The topics addressed here are varied but are equally important. Research areas summarized in this issue include families of diverse backgrounds (Kim et al., 2021; Lim et al., 2021; Rios \& Burke,

\section{Jill C. Fodstad}

jfodstad@iupui.edu

1 Indiana University School of Medicine, Indianapolis, IN, USA

2 Indiana University Health Physicians, Indianapolis, IN, USA
2021); parent-mediated intervention (Lee \& Meadan, 2021; Liao et al., 2021); diagnosis (Makino et al., 2021; McCrimmon \& Gray, 2021); measurement (Madarevic, et al., 2021); and emotional well-being (Deguchi et al., 2021; Ghanouni \& Hood, 2021). The authors not only highlight important findings that are of clinical relevance, but also note gaps in the literature that should be continued to be investigated to ensure the health and success of the family unit.

It is my hope that this issue provides you, the RJAD reader, with a highly focused and easily readable summary of the literature. The articles presented should aid you in thinking critically about how we as researchers, teachers, clinicians, providers, and other stakeholders can meet the unique and diverse needs of those with ASD and also their families. Similarly, the literature gaps identified across these articles should provide a catalyst for further research with the sole intent of ensuring that the highlighted barriers are minimized and positive experiences for all families are maximized.

\section{References}

Begum, R., \& Mamin, F. A. (2019). Impact of autism spectrum disorder on family. Autism Open Access, 9, 244.

Deguchi, N. K., Asakura, T., \& Omiya, T. (2021). Self-stigma of families of persons with autism spectrum disorder: A scoping review. Review Journal of Autism and Developmental Disorders. https:// doi.org/10.1007/s40489-020-00228-5

Ghanouni, P., \& Hood, G. (2021). Stress, coping, and resiliency among families of individuals with Autism: A systematic review. Review Journal of Autism and Developmental Disorders. https://doi.org/ 10.1007/s40489-021-00245-y

Karst, J. S., \& Van Hecke, A. V. (2012). Parent and family impact of autism spectrum disorders: A review and proposed model for intervention evaluation. Clinical Child and Family Psychology Review, 15(3), 247-277.

Kim, I., Wang, Y., Dababnah, S., \& Betz, G. (2021). East Asian American parents of children with autism: A scoping review. Review Journal of Autism and Developmental Disorders. https://doi.org/ 10.1007/s40489-020-00221-y 
Lee, J. D., \& Meadan, H. (2021). Parent-mediated interventions for children with ASD in low-resource settings: A scoping review. Review Journal of Autism and Developmental Disorders. https:// doi.org/10.1007/s40489-020-00218-7

Liao, C. Y., Ganz, J. B., Vannest, K. J., Wattanawongwan, S., Pierson, L. M., Yllades, V., \& Li, Y. F. (2021). Caregiver involvement in communication skills for individuals with ASD and IDD: A metaanalytic review of single-case research on the English, Chinese, and Japanese literature. Review Journal of Autism and Developmental Disorders. https://doi.org/10.1007/s40489-020-00223-w

Lim, N., O’Reilly, M., Sigafoos, J., Lancioni, G. E., \& Sanchez, N. J. (2021). A review of barriers experienced by immigrant parents of children with autism when accessing services. Review Journal of Autism and Developmental Disorders. https://doi.org/10.1007/ s40489-020-00216-9

Madarevic, M., Van Leeuwen, K., Warreyn, P., \& Noens, I. (2021). Conceptualisation of parenting in research on young children with or at elevated likelihood of autism: A systematic review of observational measures. Review Journal of Autism and Developmental Disorders. https://doi.org/10.1007/s40489-020-00217-8
Makino, A., Hartman, L., King, G., Wong, P. Y., \& Penner, M. (2021). Parent experiences of autism spectrum disorder diagnosis: A scoping review. Review Journal of Autism and Developmental Disorders. https://doi.org/10.1007/s40489-021-00237-y

McCrimmon, A. W., \& Gray, S. M. (2021). A systematic review of factors relating to parental satisfaction with the diagnostic process for autism spectrum disorder. Review Journal of Autism and Developmental Disorders. https://doi.org/10.1007/s40489-020-00224-9

Rios, K., \& Burke, M. M. (2021). Facilitators and barriers to positive special education experiences and health among Latino families of children with disabilities: Two systematic literature reviews. Review Journal of Autism and Developmental Disorders. https:// doi.org/10.1007/s40489-020-00220-z

Sim, A., Vaz, S., Cordier, R., Joosten, A., Parsons, D., Smith, C., \& Falkmer, T. (2018). Factors associated with stress in families of children with autism spectrum disorder. Developmental Neurorehabilitation, 21(3), 155-165.

Publisher's Note Springer Nature remains neutral with regard to jurisdictional claims in published maps and institutional affiliations. 